\title{
O Trabalho de Manutenção em uma Prefeitura Universitária: Entre Dificuldades e Realizações
}

Maintenance Work in a University City Hall: Between Difficulties and Accomplishments

El Trabajo de Mantenimiento en una Prefectura Universitaria: Entre Dificultades y Realizaciones
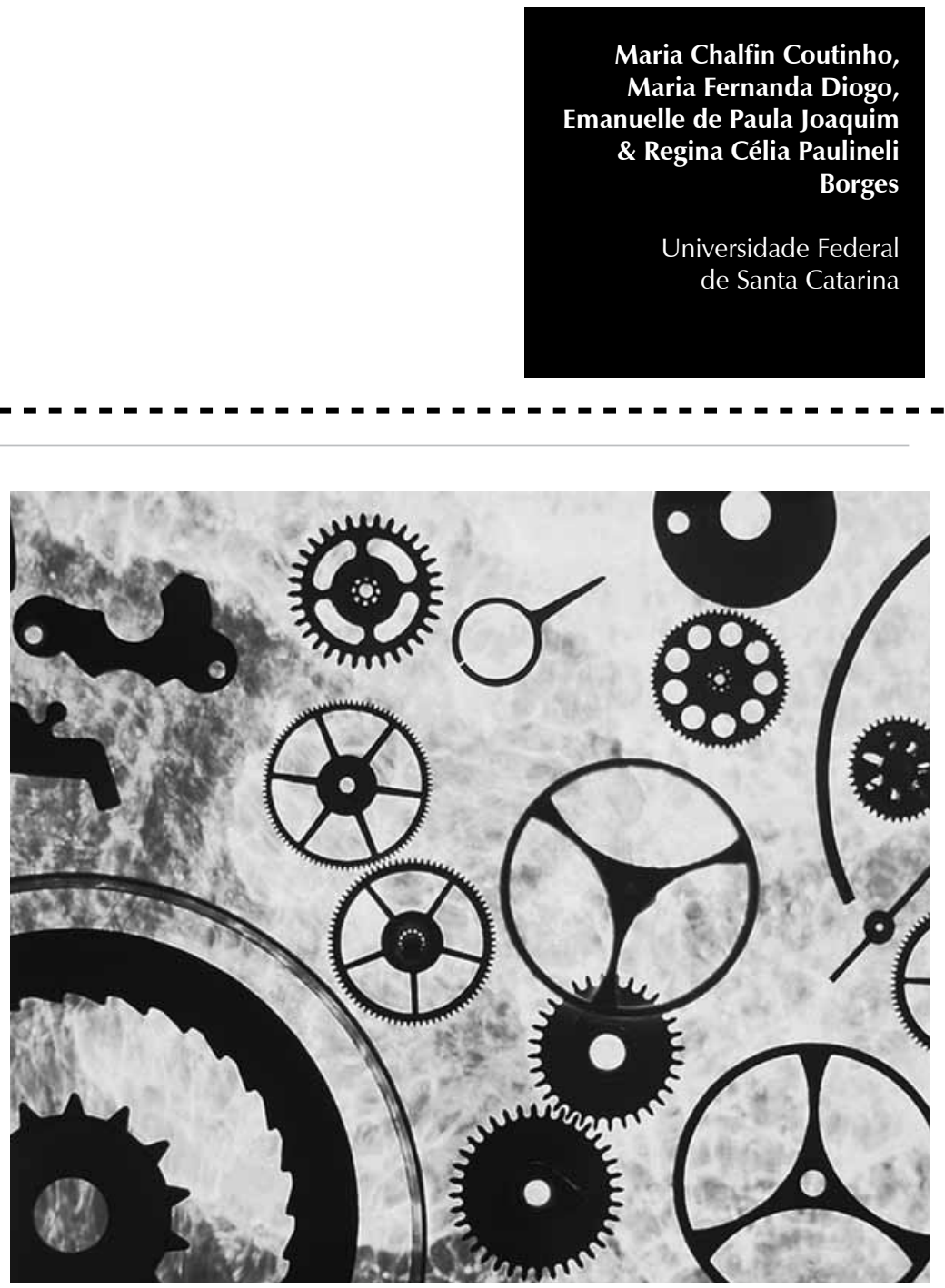
Resumo: As últimas décadas do século XX foram marcâdas por intensas transformações nos setores produtivos nacional e internacional, entre as quais se destaca o processo de reestruturação produtiva. Este atingiu tanto o setor privado como o público. O objetivo desta pesquisa foi compreender de que forma essas mudanças afetaram uma universidade pública localizada no sul do País, mais especificamente sua prefeitura universitária, e quais sentidos lhe foram atribuídos pelos servidores técnico-administrativos ligados à área de manutenção. A técnica para coleta de informações foi o grupo focal. A análise de conteúdo aplicada ao material coletado possibilitou melhor compreensão do perfil dos entrevistados e dos sentidos que atribuíam aos seus trabalhos. Delinearam-se duas categorias: cotidiano/organização do trabalho e sentidos do trabalho. Foram encontradas diversas peculiaridades referentes ao serviço público e ao modo de gestão da prefeitura. Os sujeitos se perceberam privilegiados pela estabilidade que o serviço público lhes proporcionava e viam seu trabalho como fonte de realização pessoal e sustento financeiro. Contudo, demonstraram insatisfação com o não reconhecimento do seu trabalho pela comunidade acadêmica, por trabalharem em condições físicas e humanas caracterizadas como precárias, e também narraram sentimento de vergonha associado ao estigma de serem servidores.

Palavras-chave: Satisfação no trabalho. Universidade pública. Servidor público. Grupo focal.

Abstract: The last decades of the XX century have been appointed by the intense transformations in the national and international productive sectors, among which stands out the process of productive reorganization. This research aimed at understanding the ways these changes affected a public university in the south of the country, more specifically its university City Hall, and also at understanding which senses were attributed to such changes by the public servants of the maintenance area. The technique used to collect information was the focal group. The analysis of content applied to the collected data brought a better understanding about the interviewed servants profile and about the senses they attributed to their work. Two categories were delineated: daily/organization of the work and senses of the work. Several peculiarities referring to the public service and to the management way of the City Hall were found. The interviewed people considered themselves privileged for the stability the public service provided them and understood their work as a source of personal accomplishment and financial support. However, they demonstrated discontent feelings about the lack of recognition of their work by the academic community, to the work in precarious physical and human conditions and also felt embarassed about the stigma of being public servants. Keywords: Job satisfaction. Public university. Public servants. Focal group.

Resumen: Las últimas décadas del siglo XX fueron marcadas por intensas transformaciones en los sectores productivos nacional e internacional, entre las cuales se destaca el proceso de reestructuración productiva. Éste alcanzó tanto el sector privado como el público. El objetivo de esta pesquisa fue comprender de qué forma esas mudanzas afectaron a una universidad pública localizada en el sur del País, más específicamente su prefectura universitaria, y qué sentidos le fueron atribuidos por los funcionarios técnico-administrativos relacionados con el área de mantenimiento. La técnica para recogida de informaciones fue el grupo focal. El análisis de contenido aplicado al material recogido posibilitó mejor comprensión del perfil de los entrevistados y de los sentidos que atribuían a sus trabajos. Fueron delineadas dos categorías: cotidiano/organización del trabajo y sentidos del trabajo. Fueron encontradas diversas peculiaridades referentes al servicio público y al modo de gestión de la prefectura. Los sujetos se supieron privilegiados por la estabilidad que el servicio público les proporcionaba y veían su trabajo como fuente de realización personal y sustento financiero. Sin embargo, demostraron insatisfacción con el no reconocimiento de su trabajo por la comunidad académica, por trabajar en condiciones físicas y humanas caracterizadas como precarias, y también narraron sentimiento de vergüenza asociado al estigma de ser funcionarios públicos.

Palabras clave: Satisfaccion en el trabajo. Universidad pública. Funcionario público. Grupo focal.

A dinâmica emergente nas últimas décadas do século $X X$ é retratada por estudiosos e pesquisadores como profícua em extensas e intensas transformações (Antunes, 2005; Antunes \& Alves, 2004; Mészáros, 2002). Antunes e Alves enfatizam a reestruturação produtiva, ou seja, as modificações ocorridas no antigo modelo de processo de trabalho (taylorista/fordista), que foi substituido e/ou mesclado a formas mais flexíveis de produção. Em decorrência, foi observado o crescimento de novas relações laborais por meio de trabalhos precários, informais, terceirizados e temporários. A reestruturação produtiva inseriu-se no contexto da mundialização do capital e, assim, foi aberto espaço para 
Para alguns autores (Gorz, 1982; Offe, 1989, entre outros), as mudanças contemporâneas redundaram na perda da centralidade do trabalho, contrariando a tese de Marx e Engels (1932/2006),

que prioriza o trabalho como constituinte do ser social e da atividade humana.

1 Este artigo analisa parte dos resultados da pesquisa Os sentidos do trabalho para servidores técnicoadministrativos da Universidade Federal de Santa Catarina, desenvolvida de 2006 a 2009, financiada pelo Programa Institucional de Bolsas de Iniciação Científica $\mathrm{PIBIC} / \mathrm{CNPq}-\mathrm{BIP} /$

UFSC - 2006/2009 e pelo $\mathrm{CNPq}-$ Conselho Nacional de Desenvolvimento Científico e Tecnológico 2007/2008. emergência do que Alves (2005) denominou novo e precário mundo de trabalho, com implicações para a própria configuração da classe trabalhadora. Conforme Antunes (1998), observou-se mais intensamente a "heterogeinização, fragmentação e complexificação da classe trabalhadora" (p. 42).

Para alguns autores (Gorz, 1982; Offe, 1989, entre outros), as mudanças contemporâneas redundaram na perda da centralidade do trabalho, contrariando a tese de Marx e Engels (1932/2006), que prioriza o trabalho como constituinte do ser social e da atividade humana. Adotamos no presente texto a concepção daqueles (Antunes, 2005; Alves, 2005; Mészáros, 2002; Navarro \& Padilha, 2007) que consideram o trabalho a senha para a identificação dos sujeitos, defendendo o seu caráter pluralista e central nas vidas das pessoas. Trabalhar não é somente executar uma atividade, pois nessa ação está implícita a subjetividade daquele que a executa e os relacionamentos aí estabelecidos.

Partindo dos pressupostos acima, foi desenvolvida uma pesquisa para investigar os sentidos atribuídos ao trabalho por servidores que realizavam atividades ligadas à área de manutenção em uma universidade pública brasileira localizada no sul do País. O artigo apresenta uma parcela dessa investigação ${ }^{1}$. Iniciamos com uma breve contextualização das mudanças atuais no setor público, e, em seguida, trazemos o método utilizado, os resultados da pesquisa e finalizamos com algumas considerações sobre o tema.

\section{Trajetória do serviço público brasileiro}

O serviço público, conforme Motta (2007) tem como deveres servir o cidadão e centralizar suas atuações na demanda dos usuários. Para Chanlat (2002), a natureza da prestação de serviços no setor público não é comparável à das empresas privadas, pois se trata de um tipo de serviço vinculado a questões sociais relativas à ética do bem comum. Desde a década de 1970, o modelo burocrático de administração pública vem enfrentando reestruturações em escala mundial (Castro, 2006). As mudanças mais significativas começaram a aparecer no Brasil a partir da década de 1990. O Governo Fernando Henrique Cardoso, em 1995, inaugurou uma nova forma de administração pública denominada paradigma gerencial (Magalhães, Oliveira, Abreu \& Magalhães, 2006), no qual se destacam a flexibilização, a horizontalização das estruturas e a descentralização de funções (Neves, 2005). Segundo Pires e Macêdo (2006), o paradigma gerencial tinha por objetivo fomentar uma atuação mais eficiente através da cultura da flexibilidade e da gestão empreendedora.

Para Motta (2007), a modernização no serviço público brasileiro seguiu modelos da iniciativa privada, considerados mais eficazes. O autor destaca que as técnicas importadas apresentaram grande ênfase na eliminação de atividades, na privatização, na mudança do perfil dos ingressantes no serviço público, na utilização de novas tecnologias, na redução de pessoal, no aumento da carga horária, etc. De acordo com Neves, essas transformações deslocaram o foco dos meios para os resultados.

A administração atual tem impetrado mudanças significativas nas organizações públicas federais, entre as quais as universidades. O Governo Luiz Inácio Lula da Silva implantou novas diretrizes para a gestão de carreiras, planos de cargos, política de gestão por competências e avaliações de desempenho, dentre outras medidas que buscaram estabelecer um novo referencial teórico e metodológico para a gestão do desenvolvimento dos recursos humanos da administração pública federal. Algumas dessas políticas, como a gestão por competências, assemelham-se a propostas 
implementadas em organizações privadas desde o final do século XX.

Em fevereiro de 2006, passou a vigorar o Decreto no 5.707, que institui diretrizes para o desenvolvimento de pessoal alicerçado em três instrumentos: Plano Anual de Capacitação, Relatório de Execução de Atividades e Sistema de Gestão por Competência (Brasil, 2009). Segundo o documento-base da Conferência Nacional de Recursos Humanos da Administração Pública Federal, "a construção de um Estado presente e atuante, que se contrapõe à concepção de Estado mínimo do neoliberalismo, exige um olhar abrangente e inclusivo para as carreiras e os cargos que compõem a Administração Pública Federal em toda sua complexidade" (Brasil, 2009, p. 11).

Esta pesquisa teve como foco as transformações do modo de gestão das universidades federais. As instituições universitárias atuam como prestadoras de serviços públicos e são definidas por uma tríade que representa sua funçãofim: ensino, pesquisa e extensão (Vieira \& Vieira, 2004). Para atender esses objetivos e atingir a comunidade em geral, em especial os alunos de graduação e pós-graduação, são necessários profissionais docentes e, também, um grande número de servidores técnico-administrativos (STA).

Partindo do pressuposto da articulação dialética entre as transformações do setor público e os processos de significação aí construídos, é interessante caracterizar o contexto no qual se insere a categoria profissional dos servidores públicos investigada. Assim, será apresentado, a seguir, o método da pesquisa, iniciando-se por uma breve categorização da universidade investigada, em especial a prefeitura universitária, setor responsável por manter em funcionamento a instituição de ensino em um quadro de transformações e precarização das condições de trabalho. Adiante serão discutidos os resultados da investigação e, por fim, tecidas algumas considerações sobre o tema.

\section{Método}

\section{A universidade, a prefeitura universitária e os participantes da pesquisa}

A universidade federal na qual foi realizada a pesquisa localiza-se no sul do País. Atualmente é constituída por 57 departamentos e 11 centros de ensino, possui 39 cursos de graduação, 104 de mestrado, 26 de doutorado e 88 especializações. Sua estrutura lhe permite funcionar como se fosse uma cidade: órgãos de prestação de serviços, centro de eventos, hospital universitário, clínica odontológica, gráfica, editora, planetário, observatório astronômico, fórum, horto botânico, museu, centro esportivo, templo ecumênico, bibliotecas e centenas de laboratórios.

A investigação foi realizada junto à prefeitura universitária (PU), responsável pela manutenção, conservação e efetuação de reformas em instalações dos campi universitários. A PU é administrada por um prefeito, designado pelo reitor. À época da coleta de informações, a PU apresentava 112 STA em seu quadro funcional, sendo 76 o número de terceirizados, volume alto se comparado aos outros setores universitários. Segundo informações fornecidas pela assessoria do prefeito, os terceirizados realizavam basicamente os mesmos serviços que os STA, contudo, tinham remuneração e direitos diferenciados.

Os sujeitos desta pesquisa foram seis STAs e um terceirizado. Os primeiros realizavam diversas tarefas relacionadas à manutenção da universidade (trabalhos elétricos, de alvenaria, pintura, conserto de equipamentos, etc.). Este artigo tomou como referência as informações coletadas na segunda fase da pesquisa. 


\section{A pesquisa}

A coleta das informações se dividiu em duas etapas: um grupo focal (GF) realizado com trabalhadores da PU, principal técnica utilizada, e entrevistas complementares com o prefeito, com a médica do trabalho e com uma assistente social da instituição, que buscaram elucidar alguns pontos e ampliar os conhecimentos relativos ao cotidiano e às condições de trabalho dos STA.

A técnica do GF consistiu na formação de um grupo de discussão com pessoas que possuíam características comuns (no caso, que realizavam trabalhos de conservação e manutenção na universidade). O convite foi realizado em todos os setores da $\mathrm{PU}$, e a adesão foi espontânea. A produção grupal é a maior justificativa para a utilização dessa técnica, pois possibilita a discussão e o surgimento de divergências, aquiescências e contradições no grupo (Gatti, 2005). De acordo com Carlini-Cotrim (1996), o GF permite aos participantes repensarem suas ideias, de modo a expressar e fundamentar, na discussão grupal, novas opiniões sobre o tema abordado.

Estiveram presentes nesse GF os sujeitos da pesquisa e três pesquisadoras, e o encontro foi conduzido por uma moderadora. Conforme Carlini-Cotrim, (1996) o papel do moderador é criar um ambiente de trocas de experiências, "propiciador para que diferentes percepções e pontos de vista venham à tona, sem que haja nenhuma pressão para que seus participantes votem, cheguem a um consenso ou estabeleçam algum plano". Aos pesquisadores-assistentes coube observar a conduta do grupo, realizar anotações e, eventualmente, intervir.

O discurso dos participantes foi tomado como coletividade, ou seja, não foi discriminada a fala dos participantes individualmente, pois o grupo foi compreendido como uma unidade de análise (Gatti, 2005). Realizamos a análise do conteúdo (AC) do material coletado, técnica que privilegia a mensagem do autor como ponto de partida da análise. Para Franco (2005), o objetivo da AC é buscar o(s) sentido(s) da fala por meio da criação de categorias de análise. Estas foram definidas tanto a priori (antes da realização do GF) quanto a posteriori (categorias que emergiram a partir da fala dos sujeitos). Obtivemos duas categorias: cotidiano/organização do trabalho e sentidos do trabalho. Cabe lembrar que essa divisão é uma forma de apresentar as informações colhidas e organizar a análise: o grupo se apresenta uno e indivisível em suas falas, e, dessa forma, as categorias se interpenetram em vários momentos.

Em seguida ao GF, foram realizadas três entrevistas individuais semiestruturadas: com o prefeito, com a médica do trabalho e com uma profissional do serviço social. As entrevistas foram guiadas por um roteiro norteador e seguiram um padrão de comunicação bilateral entre pesquisador e entrevistado (Zago, 2003). As informações levantadas tiveram o objetivo de complementar e possibilitar a triangulação dos dados oriundos da análise do GF.

A escolha desses dois procedimentos de coleta de informações e da técnica de análise deveu-se ao pressuposto de que toda mensagem falada, escrita ou observada contém infindáveis informações sobre seus autores e sobre seu meio. Poucos são os estudos que focalizam essa categoria profissional. Realizar uma pesquisa qualitativa na forma de estudo de caso, tendo como base as técnicas de coleta de informações descritas na perspectiva da equipe de pesquisadoras, foi a forma mais adequada para compreender a contraditória realidade laboral desse grupo específico de trabalhadores.

\section{Resultados e análise}

A seguir, são apresentados os resultados da pesquisa mesclados à análise. Nos 
Quando

novos valores antagônicos aos vigentes são incorporados, os resultados dessas alterações podem ser limitados quando há resistência através da manutenção dos valores antigos e das relações de poder anteriormente vigentes (Fleury \& Fischer, 1996). relatos dos participantes do grupo, foram encontradas informações sobre a estrutura, o funcionamento e as singularidades do tipo de trabalho executado. Em um primeiro momento, descreveu-se o cotidiano e os modos de organização do trabalho dos servidores participantes do estudo. Nesse contexto, são construídos os sentidos atribuídos ao trabalho pelos entrevistados, categoria essa apresentada na sequência.

\section{Cotidiano e organização do trabalho}

Durante o estudo, buscou-se evidenciar a cultura e os jogos de poder relativos à universidade como um todo e à $\mathrm{PU}$ em particular. A cultura de uma instituição serve de referência para a orientação do modo de agir de seus integrantes e propicia identificação entre os membros (Cruz, Queiroz, \& Sampaio, 1998). Quando novos valores antagônicos aos vigentes são incorporados, os resultados dessas alterações podem ser limitados quando há resistência através da manutenção dos valores antigos e das relações de poder anteriormente vigentes (Fleury \& Fischer, 1996). Foi observado na $\mathrm{PU}$ que, mesmo diante da implementação de um novo modelo de gestão na universidade, ainda preponderava uma cultura paternalista de gerenciamento, favorecimentos e apadrinhamentos.

Foi identificada, nos discursos dos participantes do GF e na entrevista com o prefeito, uma ampla gama de posturas paternalistas. O serviço público brasileiro mantém características como o personalismo e o paternalismo, centralizando o poder na figura do dirigente e não no resultado da gestão de recursos inerentes a estruturas formais (Motta, 2007). Segundo informou o prefeito: "(O gestor tem que ter) receptividade com relação a abrir as portas para atender todo e qualquer tipo de problema, seja de ordem familiar ou de ordem profissional, sempre aberto pra tal, mas, ao mesmo tempo, sempre sendo inflexível nas questões relativas ao trabalho". Esse recorte evidencia mescla entre questões profissionais e pessoais no cotidiano administrativo da PU. No GF, ficou evidenciado o quanto era comum serem tomadas decisões organizacionais a partir de critérios extra-oficiais, como nos casos de dispensa de funcionários com problemas pessoais ou quando se decidia quem seria o responsável por resolver alguma urgência no campus.

Pires e Macedo (2006) comentam que o paternalismo permanece como especificidade das organizações públicas, marcadas pelos interesses políticos dos dirigentes na distribuição de pessoal, empregos e cargos. Segundo Neves (2005), apesar das novas práticas administrativas, o viés paternalista ainda é característica das práticas gerenciais da administração pública brasileira. Esse autor ressalta que, na cultura do serviço público, destaca-se o jeitinho brasileiro, definido como o distanciamento entre as normas legais e as práticas gerenciais.

Para os servidores presentes no GF, o apadrinhamento aumentava a perspectiva de um STA conquistar promoções ou algumas benesses. "Aquela questão, aí eu sou protegido de um, o outro é protegido do outro (...), acaba no final ficando uma panela só, porque ninguém quer se incomodar". Essa questão é recorrente na literatura sobre serviço e servidores públicos. Neves (2005) destaca que a presença de padrinhos ainda é muito comum no serviço público. Para Codo (2002), o avanço na carreira pública dificilmente exige competências, habilidades ou capacidade de cooperação. Pires e Macêdo (2006) destacam que, mesmo se mérito e qualificação forem valores almejados pela instituição, têm mais chances de serem bem sucedidos aqueles servidores apadrinhados politicamente. Pesquisa realizada por Cruz, Queiroz e 
Sampaio (1998) em outra universidade federal identificou grande insatisfação dos servidores relacionada à escolha dos cargos de chefias por apadrinhamentos, demonstrando ser essa uma prática recorrente.

Os trabalhos desenvolvidos pelos participantes do GF são de conservação e manutenção. As atividades de apoio são as bases do desenvolvimento e da concretização das atividades-fim da instituição, como afirmam Vieira e Vieira (2004). Os STA relataram, demonstrando orgulho e satisfação, que seus trabalhos "garante $(m)$ a manutenção e o funcionamento das salas de aula. (...) Só vai desencalhar o seu trabalho lá como professora, como pesquisadora (apontando para a moderadora), se um de nós estiver de plantão".

Eles demonstraram ter consciência da importância de seus trabalhos para a universidade.

Contudo, uma das especificidades desse tipo de trabalho é a sua distinção em relação aos objetivos-fim da universidade (ensino, pesquisa e extensão). Esses STA frequentemente interrompem as atividades acadêmicas, pois seus trabalhos são ruidosos, sendo necessária a suspensão da aula ou da pesquisa para a execução dos serviços de manutenção. Os STA narraram que nem sempre a equipe era bem recebida pelo próprio demandante: "eles mandam uma ordem de serviço pra gente consertar, a gente chega educadamente, pede licença e o cara toca nós pra fora, ele pede pra nós sair porque ele tá dando aula, só que pra mim fazer o trabalho que ele pediu eu tenho que tá dentro da sala dele". Evidenciou-se aqui um paradoxo: ao mesmo tempo em que esse trabalho é profundamente necessário para o bom funcionamento da universidade e dá orgulho para o trabalhador, ele atrapalha e nem sempre é bem recebido pelo demandante do serviço. Essa dicotomia dificulta o estabelecimento de uma dinâmica de reconhecimento pelo trabalho executado (Dejours, 1999) e aumenta a sensação de estranhamento existente entre os trabalhadores da PU e os demais STA.

O não reconhecimento desse tipo de trabalho pela comunidade acadêmica corrobora os resultados de pesquisa realizada por Coutinho, Diogo e Joaquim (2008). As autoras detalharam as dificuldades ligadas ao reconhecimento do trabalho de manutenção salientando que este se evidencia no negativo (diante de um defeito, de um mau funcionamento). Segundo os participantes do GF, seus trabalhos eram desvalorizados pelos usuários do serviço e pela própria instituição: "pra universidade, não interessa o meu trabalho pra ela, (...) eles não valorizam como deviam valorizar".

Evidenciou-se o isolamento físico e relacional do restante da universidade. A PU localizavase na periferia do campus, e isso poderia ser apontado como fator potencializador dessa sensação de distanciamento. Foi constatado que alguns servidores da $\mathrm{PU}$ se sentiam diferentes dos demais, tratando a questão como se houvesse dois lados: o lado de lá e o lado de cá. Eles próprios levantaram uma hipótese para essa sensação de diferença: "a prefeitura é um órgão que praticamente não tem nada a ver com a universidade. $A$ universidade funciona de um jeito, a prefeitura funciona de outro". Ao investigar um grupo industrial com diferentes unidades produtivas, Coutinho (2006) identificou uma pequena unidade, denominada no estudo fábrica esquecida, também localizada distante das outras unidades, com uma estrutura física inadequada e com atividades consideradas mais simples e, como consequência, havia maior dificuldade de integração com o restante da organização.

Os entrevistados comentaram que seus trabalhos eram realizados em condições inadequadas: "se alguém se apoiar na parede, ela cai, não tem condições de trabalhar dentro 
do nosso local de trabalho". Contudo, eles percebiam abundância de recursos em outros setores: "então, quer dizer, existe uma ociosidade de um lado (restante da universidade) e falta de outro (PU). (...) Lá de um lado tem bastante, do outro lado, não tem". Foi possível inferir que os entrevistados se ressentiam pelo isolamento e pela falta de destinação de recursos, compreendidos como representativos do não-reconhecimento de seus trabalhos.

Os participantes do GF narraram que seu cotidiano era atravessado por especificidades vinculadas ao funcionalismo público. Dentre elas, destacam-se questões relacionadas à autonomia e à licitação (a interferência do processo de licitação nos sentidos atribuídos ao trabalho será discutida no próximo item). A autonomia foi representada principalmente pela estabilidade empregatícia, pois esta permitia programação financeira em longo prazo: "com esse empreguinho aqui, com todo esse tormento, eu consegui colocar a minha filha na faculdade, (...) porque eu sei que durante aquele período eu estaria aqui". Contudo, os participantes do grupo afirmaram que recebiam cada vez mais cobranças por produção, fato corroborado por Neves (2005). Essas cobranças surgiam a despeito das precárias condições de trabalho, da falta ou inadequação dos materiais necessários ao trabalho. "Daí lá fora eles ficam falando: 'ah, o pintor é devagar, é isso, é aquilo', mas pintura é devagar (...) dá uma mão, lixa a parede, dá outra, tem que retocar. (...) E ainda material ruim... aí vem a cobrança."

Os servidores também se queixaram por não receberem informações sobre os cursos de capacitação ofertados pela instituição. Segundo os participantes, as chefias filtrariam esses avisos, pois havia carência de STA nos setores, o que dificultava a dispensa dos funcionários: "se eu e ele for fazer um curso e nós for perder 2 horas, 3 horas do nosso trabalho, automaticamente vai atrasar um dia de trabalho e atrasando o nosso, vai vir a cobrança em cima dele (chefe)." Outro aspecto enfatizado foi o temor de que o STA se tornasse mais qualificado que a própria chefia: "o pessoal tem medo, quem tá recebendo essa informação (sobre o curso), tem medo de passar porque acha que talvez vai ficar em termos hierárquicos mais baixos." Conforme Cruz Queiroz e Sampaio (1998), cabe aos responsáveis pelos processos administrativos facilitar o acesso dos servidores a informações técnicas e científicas, melhorando a efetividade e a qualidade do serviço oferecido. Segundo os participantes do GF, isso não ocorria, e o serviço público perdia em eficácia com essas manobras político-administrativas. Esse ponto de vista não é corroborado pela chefia, segundo a qual havia oportunidades de capacitação.

\section{Sentidos do trabalho}

O trabalho foi visto, na discussão do GF, como fonte de realização pessoal e de sustento financeiro familiar. "Pra mim, (trabalho) é tudo. É compromisso, é fidelidade, é tudo. (...) Sem o trabalho, eu não tenho nada, né (...) tem que trabalhar pra adquirir alguns bens". A importância subjetiva do trabalho também foi destacada: "trabalho faz parte da nossa vida aqui na Terra. (...) Eu adoro aquela profissão que eu faço, é minha vida". O trabalho, no sentido ontológico, é indispensável à vida humana (Marx \& Engels, 1932/2006). Apesar de ter sido narrado como difícil, precário e cheio de percalços, o trabalho demonstrou ser importante e central na fala dos participantes desta pesquisa.

Os trabalhadores participantes do GF utilizaram várias vezes a expressão sucateamento ao se referirem ao trabalho. Sucata, dentre outros significados, é "ferrovelho, (...) objeto deteriorado" (Ferreira, 2006, p. 753). Percebeu-se que eles falavam justamente da deterioração tanto do trabalho e da máquina pública (instalações, condições 
de trabalho) como dos trabalhadores (saúde física e qualificação profissional). A situação foi resumida da seguinte forma: " $O$ sucateamento que eu digo, que eu disse no início, é exatamente isso: o sucateamento total, tanto humano quanto de material, de tudo". Esses trabalhadores demonstraram sentir a falta de investimento da instituição em relação à destinação de recursos, sejam materiais, sejam humanos, e à qualificação. Os serviços de apoio e conservação nas organizações públicas estão tendo seus postos de trabalho extintos e seus conteúdos integrados ao trabalho técnico (Neves, 2005) ou terceirizados para a iniciativa privada, como se pôde observar nos serviços de limpeza e conservação dessa universidade e em boa parte dos serviços de manutenção.

A redução de STA nos setores gerou evidente sobrecarga de trabalho: "(antes) nós tinha corpo de gente pra trabalhar. Hoje a dificuldade (...) é grande. Não tem um corpo de gente pra trabalhar". A reforma do Estado tem reduzido a sua capacidade em garantir direitos e prestar serviços devido à redução do dinheiro empregado em gastos sociais, direitos previdenciários, número de servidores, etc (Neves, 2005). Nos relatos, foram percebidas queixas em relação ao aumento do volume de trabalho devido à escassez de servidores nos setores e paralela ampliação da estrutura física dos campi (aumento no número de cursos, vagas, etc.): "há vinte anos atrás, a gente consertava de três a cinco ar condicionado por semana. Hoje, eu sozinho, conserto dez por dia. (...) A universidade cresceu muito, e o número de funcionários diminuiu".

Foi possível observar que a terceirização passou a ser uma realidade na composição das equipes. Os integrantes do GF comentaram considerar essa forma de flexibilização da produção e do capital uma espécie de exploração dos trabalhadores terceirizados, pois estes realizavam o mesmo rol de tarefas que os STA, contudo, recebiam menores salários e possuíam menos benefícios. "Eu queria que ele (terceirizado presente no GF) fosse um servidor como eu, com os mesmos direitos meus. Ele é um escravo do patrão, o patrão ganha uma montoeira e ele ganha o que?" Observou-se também, assim como destacou Chanlat (2002), a contribuição da terceirização para a fragmentação das equipes de trabalho, pois havia grande rotatividade dos terceirizados. Mesmo que esse profissional fosse qualificado, ele não pertencia ao quadro institucional e, portanto, não tinha estabilidade.

Outro sentido do sucateamento apareceu associado à falta de materiais adequados. "Não tem material (...) ou (aquele que tem) é de qualidade baixa". Todas as compras no serviço público são realizadas sempre por meio do processo de licitação, e, como o critério de compra está atrelado ao menor preço, alguns materiais possuem baixa qualidade e ocasionam dificuldades na execução das tarefas e constantes retrabalhos. "Por exemplo, isso aqui eu gasto dois galões (de tinta) pra pintar e lixar essa peça toda. Com o nosso material aqui, vai outro e vai outro. Quer dizer, a mão de obra dobra porque o material é ruim". O uso de materiais de baixa qualidade dificulta a realização das atividades, bem como a burocracia do processo atrasa o serviço. Esses fatos fazem com que esses trabalhadores sejam vistos como ineficientes pelo restante da instituição.

De acordo com Pires e Macêdo, (2006) a prestação de serviços na organização pública vive uma contradição: de um lado, esta tem como missão oferecer serviços à comunidade, de outro, percebe-se inviabilizada pela falta de recursos. Uma característica típica das instituições públicas, na visão de Codo, (2002) é a lentidão dos processos administrativos. Para o autor, na maioria das vezes, o tempo gasto na realização das tarefas supera a necessidade que o procedimento exige. Observou-se, 
na área de manutenção dessa universidade pública, que a lentidão no conserto dos equipamentos pela falta de peças ou excesso de trabalho contribuía para a manutenção do estereótipo de servidor malandro, conforme relataram os entrevistados: "(um reparo) pode levar uma semana, pode levar 15 dias, pode levar um ano (...) aí o pessoal cobra da gente". A escassez de mão de obra e de materiais reforça a imagem depreciativa da sociedade sobre o servidor (Spilki \& Tittoni, 2005).

A falta de atualização dos conhecimentos também foi debatida pelo grupo: "O sucateamento é total, tão até barrando nós do nosso próprio conhecimento (...) Porque a tecnologia muda (...) Hoje tu vai fazer manutenção num ar condicionado split (...) tu vai pegar uma placa eletrônica, (...) vai pegar o manual, tá em inglês". À época da coleta de informações desta pesquisa, foi observado que a universidade não oferecia cursos de informática e inglês para esses STA. A falta de capacitação desqualifica o servidor e reforça, mais uma vez, o estereótipo social de incompetência ou má vontade (Cruz, Queiroz \& Sampaio, 1998). Os servidores buscavam orientação para realizarem reparos em aparelhos que não conheciam com colegas de fora da universidade ou se amparavam no conhecimento tácito (Coutinho, Diogo, \& Joaquim, 2008) que circulava entre os pares.

A falta de servidores e as condições de trabalho precárias acarretavam, segundo os entrevistados, problemas de saúde e riscos de acidentes: "os cilindros de oxigênio, acetileno têm que ficar na parte externa do ambiente, têm que chegar até a gente através de tubulações pela norma de segurança; lá tá do nosso lado, liga o maçarico, é uma bomba". Mais uma vez, instaura-se um paradoxo: o mesmo trabalho que é fonte de sustento familiar e orgulho pode vir a comprometer a saúde física do trabalhador. Em pesquisa desenvolvida no mesmo contexto, foi possível observar o quanto estar exposto a condições inadequadas de trabalho traz riscos para a saúde dos trabalhadores (Coutinho, Diogo \& Joaquim, n.d.).

Apesar de ter sido abordada no GF uma série de dificuldades relacionadas ao trabalho, percebeu-se que os STA valorizavam seu trabalho e o reconheciam como base do funcionamento da universidade. "O cara descobriu a cura do câncer, aqui na universidade, né, trabalhando com os ratinhos lá, mas ele depende de nós também, (...) precisa da tomada funcionar, porque, se não tiver chegando energia elétrica, como é que ele vai ligar o computador. (...). Toda a universidade gira em torno do nosso trabalho". As atividades de apoio são imprescindíveis para melhor desempenho das atividades-fim, e, por esse motivo, precisam de modernizações (Vieira \& Vieira, 2004).

O discurso do grupo também expôs a importância do cumprimento de seus trabalhos como uma forma de retribuir o que a sociedade em geral neles investe, afinal, "é a comunidade que paga nosso trabalho. (...). Não é a universidade que paga, é o povo". Chanlat (2002) atribui essa característica exclusivamente ao serviço público, e chama-a de "ética do bem comum". Para o autor, trabalhar em prol da sociedade serviria de motivação para os funcionários públicos. De acordo com Vieira e Vieira (2004), o poder público representa a sociedade, o que poderia explicar o sentido de contribuição social tão presente nas falas do GF. Do mesmo modo, Morin, Tonelli e Pliopas (2007) concluíram que um dos sentidos que o trabalho pode assumir nas vidas dessas pessoas é a dimensão social, na medida em que esse trabalhador serve à sociedade.

Uma significação marcante que emergiu no GF relativa à especificidade do trabalho no serviço público foi a da contradição: ser servidor público ora foi descrito como motivo de orgulho/honra, de servir à sociedade, de ser útil à instituição, ora foi narrado como 
motivo de vergonha/humilhação, resultados análogos aos encontrados em Coutinho, Diogo, e Joaquim (2008). A honra e o orgulho advieram do fato de trabalhar em uma universidade pública e de servir à sociedade. Para Chanlat, (2002) o "orgulho de pertencer a uma categoria que se define pelo serviço dos outros é (...) o que fundamenta a ação de utilidade pública no que ela tem de mais específico, a ética do interesse geral e a defesa da justiça" (p. 7). Contudo, a vergonha e a humilhação também advieram dessa mesma inserção laboral como resultado da má conduta de alguns servidores. Segundo os entrevistados, essas ocorrências eram mais comuns no passado, mas contribuíram para dar uma significação pejorativa à categoria dos servidores públicos, associando-os à imagem de funcionários sem muito interesse pelo trabalho, a mandriões, com pouca produtividade e bastante preocupados com seus privilégios: "a discriminação é muito grande, tem certos casos que a gente sai humilhado (...) em determinadas regiões ou locais, eu tenho até vergonha de dizer que eu trabalho no serviço público". Spilki e Tittoni (2005) ressaltam que, em tempos de alto índice de desemprego, essa categoria é vista como socialmente privilegiada. Tal fato contribuiria, segundo Chanlat, (2002) para a opção que alguns servidores fazem de esconder sua condição profissional.

\section{Considerações finais}

O grupo de trabalhadores investigado atribuiu valoração positiva às suas atividades, reconhecendo-as como importantes para sua vida pessoal e familiar (realização pessoal e sobrevivência) bem como para a instituição na qual trabalhavam (realização profissional) e, ainda, evidenciaram a contribuição social de seus trabalhos. Esses servidores consideraram a manutenção essencial para a concretização das atividades-fim da instituição, entretanto, afirmaram que a comunidade universitária em geral não reconhecia sua relevância ou ignorava seu trabalho. Eles atribuíram essa significação às grandes diferenças existentes entre os trabalhos de manutenção e os dos demais servidores. É expressivo ressaltar a importância do reconhecimento da esfera laboral na vida do sujeito como forma de fazer o trabalhador sentir-se útil e socialmente valorizado, além de contribuir para a construção de sua identidade.

A questão da falta de material e/ou da baixa qualidade dos mesmos remontou à burocracia das organizações públicas, nesse caso, destacou-se, principalmente, o processo de licitação. Segundo os entrevistados, nos últimos anos, ocorreu a ampliação do volume de trabalho devido à diminuição do quadro de STA e à paralela ampliação dos campi. A redução de STA implicou a elevação do número de trabalhadores terceirizados. Todos os participantes da pesquisa, tanto os STA como o trabalhador terceirizado, concordaram que essa forma de flexibilização do trabalho visava à exploração desse prestador de serviços e à maior lucratividade do empregador. Os entrevistados destacaram o sucateamento da universidade relativo ao desgaste físico/mental dos trabalhadores e à deterioração da máquina estatal.

O sucateamento da universidade, tanto em termos humanos como materiais, poderia estar associado ao contexto de diminuição da máquina pública vigente no País desde os anos 90. Em decorrência de uma política de corte neoliberal, houve um incremento das privatizações (Antunes \& Alves, 2004). Mesmo mantendo-se como instituições públicas, as universidades passaram por desgaste e ausência de investimento, característicos do período. Essas políticas foram vivenciadas no cotidiano de trabalho de nossos entrevistados através da diminuição de quadros, terceirização, material escasso ou de pouca qualidade, sobrecarga de trabalho, etc.

Em relação aos sentidos atribuídos ao 
trabalho, os STA comentaram a contradição orgulho versus humilhação. O orgulho se deveu ao fato de eles trabalharem em uma instituição federal, serem funcionários públicos, servirem à sociedade bem como possuírem estabilidade empregatícia e poderem programar sua vida financeira. A humilhação surgiu dos estereótipos criados em relação ao serviço público: o de mandrião e barnabé, daquele que não exerce a contento suas atividades. A visão negativa do servidor público, frequentemente veiculada na mídia até hoje, também ganhou impulso com a implantação de políticas neoliberais a partir do governo Collor, conhecido como o caçador de marajás, cujo triste desfecho é de conhecimento público. Nesse sentido, os sentimentos de orgulho presentes nos discursos dos trabalhadores poderiam ser compreendidos como forma de resistência às humilhações.

O cotidiano desses servidores também era perpassado por pontos específicos do funcionalismo público e da cultura da instituição. Apesar de a universidade estar vivenciando processos de modernização e de novas práticas gerenciais, o apadrinhamento foi uma característica que se mostrou bastante evidente na $\mathrm{PU}$, bem como o paternalismo centrado na figura do prefeito, fazendo com que, em alguns casos, aspectos da vida privada interferissem nas relações de trabalho. A presença de práticas de gestão tradicionais seria um dos elementos encontrados por esse coletivo de trabalhadores para resistir às pressões sociais por desqualificação de sua identidade laboral.

Uma peculiaridade da PU era a realização de trabalhos de conservação e manutenção. Os servidores descreveram esse tipo de trabalho como uma atividade que dependia da colaboração de todos os setores da prefeitura, o que proporcionava maior eficiência. Outra característica típica dessa atividade, relatada pelo grupo, é que, ao desempenhá-la, o servidor atrapalhava as demais tarefas realizadas na proximidade devido ao barulho e à necessidade de paralisação de algumas atividades acadêmicas. Dessa forma, é possível perceber outra contradição: ao mesmo tempo em que os servidores forneciam suporte às atividades-fim, eles as atrapalhavam enquanto executavam suas tarefas, o que evidenciava outra forma de ambivalência na sua vida profissional. Aqui cabe questionar o lugar reservado pela instituição para quem exerce atividades de apoio e o quanto a dissociação entre estas e as atividades-fim pode levar ao isolamento e à separação entre os dois lados, o de lá e o de cá, como bem expressaram os entrevistados, o que pode levar a prejuízos para o alcance das próprias atividades-fim da universidade.

Ainda foi observada a falta de investimento da instituição nos trabalhadores da área de manutenção. Eles narraram isolamento físico e relacional relativo à especificidade do seu trabalho, seu não reconhecimento pela comunidade acadêmica e a ineficácia na divulgação dos cursos de capacitação oferecidos pela universidade, pois eram os últimos a receber quaisquer informações sobre eventos, cursos e palestras. Os servidores destacaram a falta de atualização para a execução eficaz dos trabalhos e a grande carência de treinamento, o que potencializa a sensação de ineficiência e o despreparo desses profissionais. A deficiência de pessoal nos setores também era um fator, segundo eles, que impedia o afastamento e dificultava a participação nos cursos, pois deixaria postos de trabalho descobertos. A falta de capacitação fez com que alguns servidores se tornassem tutores dos colegas, assim, o conhecimento necessário para a execução do trabalho era adquirido, principalmente, na prática diária, na troca de conhecimentos entre companheiros e também com pessoas de empresas externas à universidade, em uma troca de favores entre colegas. Aqui vemos a emergência do saber tácito, do conhecimento 
adquirido na prática (Coutinho Diogo, \& Joaquim 2008), muitas vezes menos valorizado do que os saberes formais advindos de programas de capacitação oferecidos pela instituição.

Entre dificuldades e realizações, esses servidores interpretam dialeticamente seus trabalhos de forma singular e, também, em um movimento coletivo e social. Mediante essa realidade complexa, heterogênea e em transformação, ainda conferem lugar central às suas atividades laborais e buscam contribuir para o pleno funcionamento da universidade. Assim, esta pesquisa teve como objetivo dar visibilidade a essas vivências que subsidiam nosso fazer acadêmico e fomentar novas reflexões sobre o tema.

\section{Maria Chalfin Coutinho}

Doutora em Ciências Sociais pela UNICAMP, Professora da Graduação e do Programa de Pós-Graduação da Universidade Federal de Santa Catarina. Bolsista Produtividade pelo CNPq, Santa Catarina - SC - Brasil.

E-mail: chalfin@linhalivre.net

\section{Maria Fernanda Diogo}

Mestre em Psicologia, Doutoranda pelo Programa de Pós-Graduação da Universidade Federal de Santa Catarina, SC - Brasil.

E-mail: mafediogo@bol.com.br

\section{Emanuelle de Paula Joaquim}

Graduação em Psicologia, Mestranda pelo Programa de Pós-Graduação da Universidade Federal de Santa

Catarina, SC - Brasil.

E-mail: chestnuts_hd@hotmail.com

\section{Regina Célia Paulineli Borges}

Mestre em Psicologia, Psicóloga, Santa Catarina - SC - Brasil.

E-mail: reginacl@uol.com.br

\section{Endereço para envio de correspondência:}

R. Dep. Antônio Edu Vieira no 1304 apto 202A - Florianópolis - SC - Brasil CEP: 88040-001

Recebido 9/10/2009, 1a Reformulação 6/6/2010, Aprovado 4/7/2010

Referências
Alves, G. (2005). O novo (e precário) mundo do trabalho: reestruturação produtiva e crise do sindicalismo. São Paulo: Boitempo.

Antunes, R. (1998). Adeus ao trabalho?: ensaio sobre as metamorfoses e a centralidade do mundo (5a ed.). São Paulo: Cortez.

Antunes, R. (2005). O caracol e a sua concha: ensaios sobre a nova morfologia do trabalho. São Paulo: Boitempo.

Antunes, R. L. C., \& Alves, G. (2004). As mutações no mundo do trabalho na era da mundialização do capital. Educação \& Sociedade, 25(87). Recuperado em 27 de agosto 2007, de http://www.scielo.br/scielo.php?script=sci_arttext\&pid=S0 $10173302004000200003 \&$ lng $=$ en\&nrm=iso
Brasil (2009).Texto Base da Conferencia Nacional de Recursos Humanos na Administração Pública. Ministério do Planejamento, Orçamento e Gestão, Secretaria de Recursos Humanos: República Federativa do Brasil.

Carlini-Cotrim, B. (1996). Potencialidades da técnica qualitativa grupo focal em investigações sobre abuso de substâncias. Revista de Saúde Pública, 30(3). Recuperado em 28 março 2009, de http://www.scielosp.org/scielo.php?pid=S0034$89101996000300013 \&$ script $=$ sci_arttext

Castro, R. B. de. (2006). Eficácia, eficiência e efetividade na administração pública. In 30 Encontro Anual da Associação Nacional de Pós-Graduação e Pesquisa em Administração. Salvador, BA. Recuperado em 8 maio 2007, da Anpad (Associação Nacional de Pós-Graduação e Pesquisa 
em Administração): http://www.anpad.org.br/evento. php?acao $=$ trabalho\&cod_edicao_subsecao $=149 \&$ cod_ evento_edicao $=10 \&$ cod_edicao_trabalho $=5281$

Chanlat, J-F. (2002). O gerencialismo e a ética do bem-comum: a questão da motivação para o trabalho nos serviços públicos. In 7 Congreso Internacional del CLAD sobre la Reforma del Estado y de la Administración Pública, (pp. 1-9). Recuperado em 4 julho 2008, da Unpan (United Nations Public Administration Network): http://unpan1.un.org/ intradoc/groups/public/documents/clad/clad0043316.pdf

Codo, W. (2002). A arte de não fazer. O funcionário público faz o que precisa ser feito? In M. G.

Jacques, \& W. Codo, Saúde mental e trabalho: leituras (pp. 296-308). Petrópolis, RJ: Vozes.

Coutinho, M. C. (2006). Participação no trabalho. São Paulo: Casa do Psicólogo.

Coutinho, M. C., Diogo, M. F., \& Joaquim, E. de P. (2008). Sentidos do trabalho e saber tácito: estudo de caso em universidade pública. Revista de Psicologia da Vetor Editora, 9(1), 99-108.

Coutinho, M. C., Diogo, M. F., \& Joaquim, E. de P. (no prelo). Cotidiano e saúde no trabalho: um estudo com trabalhadores que atuam na manutenção de uma universidade pública. Estudos de Psicologia de Campinas.

Cruz, M. V. G. da, Queiroz, J. A. de F., \& Sampaio, J. dos R. (1998). Cultura organizacional: um estudo sobre a administração pública de Minas Gerais. In I. B. Goulart, \& J. dos R. Sampaio (Orgs.), Psicologia do trabalho e gestão de recursos humanos: estudos contemporâneos (pp. 245 288). São Paulo: Casa do Psicólogo.

Dejours, C. (1999). Conferências brasileiras: identidade, reconhecimento e transgressão no trabalho. São Paulo: Fundap.

Ferreira, A. B. de H. (2006). Mini-Aurélio: o dicionário da língua portuguesa. Curitiba: Positivo.

Fleury, M. T. L., \& Fischer, R. M. (Orgs.). Cultura e poder nas organizações (2a ed.). São Paulo: Atlas.

Franco, M. L. P. B. (2005). Análise de conteúdo. Brasília, DF: Liber Livro.

Gatti, B. A. (2005). Grupo focal na pesquisa em ciências sociais e humanas. Brasília, DF: Liber Livro.

Gorz, A. (1982). Adeus ao proletariado. Rio de Janeiro: Forense.

Magalhães, E. M. de, Oliveira, A. R., Abreu, S. M., \& Magalhães, E. A. de. (2006). Política de treinamento dos técnicos de nível superior da Universidade Federal de Viçosa na percepção de ex-dirigentes da instituição. In 30 Encontro Anual da Associação Nacional de Pós-Graduação e Pesquisa em Administração. Salvador, BA. Recuperado em 13 maio 2007, de Anpad (Associação Nacional de Pós-Graduação e Pesquisa em Administração):http://www.anpad.org.br/evento. php?acao $=$ trabalho\&cod_edicao_subsecao $=149 \&$ cod evento_edicao $=10 \&$ cod_edicao_trabalho $=5327$
Marx, K., \& Engels, F. Engels, F. (1932/2006). A ideologia alemã: Feuerbach - a contraposição entre as cosmovisões materialista e idealista (F. Müller, Trad.). São Paulo: Martin Claret (Trabalho original publicado em 1932).

Mészáros, I. (2002). Para além do capital. (P. S. Castanheira, \& S. Lessa, Trad.). São Paulo: Boitempo; Campinas, SP: Editora da Unicamp.

Morin, E., Tonelli, M. J., \& Pliopas, A. L. V. (2007). O trabalho e seus sentidos. Psicologia \& Sociedade, 19(1), 47-56.

Motta, P. R. (2007). A modernização da administração pública brasileira nos últimos 40 anos. Revista de Administração Pública, 41 (especial). Recuperado em 12 junho 2008, http:// www.scielo.br/scielo.php?script $=$ sci_arttext\&pid $=$ S0034$76122007000700006 \& \operatorname{lng}=\mathrm{pt} \& \mathrm{nrm}=\mathrm{iso} \& \mathrm{t} \operatorname{lng}=\mathrm{pt}$

Navarro,V. L., \& Padilha,V. (2007). Dilemas do trabalho no capitalismo contemporâneo. Psicologia \& Sociedade, 19(especial), 14-20.

Neves, J. M. (2005). A face oculta da organização: a microfísica do poder na gestão do trabalho. Porto Alegre: Sulina.

Offe, C. (1989). Trabalho e sociedade. Rio de Janeiro: Tempo Brasileiro.

Perez, A. L. F., \& Pozzebon, E. (2003). Aplicação de sistema multiagente no processo de licitação. In 2 Internacional Information and Telecomunication Technologies Syposium, Florianópolis, Recuperado em 27 agosto 2008 de htpp:// www.das.ufsc.br/ eliane/artigo/perez03b.pdf

Pires, J. C. de S., \& Macêdo, K. B. (2006). Cultura organizacional em organizações públicas no Brasil. Revista de Administração Pública, 40(1). Recuperado em 16 junho 2008, de http:// www.scielo.br/pdf/rap/v40n1/v40n1a05.pdf

Presidência da República. Casa Civil. Subchefia para Assuntos Jurídicos. (1993). Lei no 8.666. Brasília: DF. Recuperado em 27 agosto 2008, de Presidência da República :http://www. planalto.gov.br/ccivil_03/LEIS/L8666cons.htm

Spilki, A., \& Tittoni, J. (2005). O modo-indivíduo no serviço público: descartando ou descartável? Psicologia \& Sociedade, 17(3), 67-73.

Vieira, E. F., \& Vieira, M. M. F. (2004). Funcionalidade burocrática nas universidades federais: conflito em tempos de mudança. RAC, 8(2). Recuperado em 7 novembro 2007, de Anpad (Associação Nacional de Pós-Graduação e Pesquisa em Administração): http://anpad.org.br/periodicos/arq_pdf/211. pdf

Zago, N. (2003). A entrevista e seu processo de construção: reflexões com base na experiência prática de pesquisa. In $\mathrm{N}$. Zago, M. P. Carvalho, \& R. A. T. Vilela (Orgs.), Itinerários de pesquisa: perspectivas qualitativas em sociologia da educação (pp. 287-309). Rio de Janeiro: DP\&A. 